\title{
Mechanism of Joint Formation and Characteristics of Interface in Ultrasonic welding: Literature Review
}

\author{
Bharat Sanga ${ }^{1}$, Reeta Wattal ${ }^{2}$, D. S. Nagesh ${ }^{3}$ \\ ${ }^{1}$ Faculty, Department of Mechanical Engineering, Guru Nanak Dev Institute of Technology, Delhi, India \\ ${ }^{2,3}$ Professor, Department of Mechanical Engineering, Delhi Technological University, Delhi, India
}

\begin{tabular}{l} 
Article Info \\
\hline Article history: \\
Received Jan 27, 2018 \\
Revised May 3, 2018 \\
Accepted May 14, 2018 \\
\hline Keyword: \\
Ultrasonic welding \\
Ultrasonic metal welding \\
Intermetallic compound \\
Heat affected zone \\
Thermo-mechanical affected \\
zone \\
Welding interface
\end{tabular}

\begin{abstract}
The study of ultrasonic welding has been going on for more than 50 years. The mechanism of joint formation and characterization of the interface in ultrasonically made joints between metal sheets and wires have been the most thought-provoking area for the researchers. The study of post-welding microstructure, the formation of any intermetallic compound at the interface and their effect on the joint strength, the presence of heat affected zone in the ultrasonically joined sheets has been explored but still, arguably the least understood. Interface characteristics are different in similar and dissimilar combinations of metals. This work presents a comprehensive review of literature regarding the studies on the microstructural analysis at the interface of the joints made by ultrasonic welding on different combinations of metal sheets. Additionally, this paper provides an analysis of the observations made by different scientists that promotes the future scope of research in this area. The study has been confined to ultrasonic metal welding only.
\end{abstract}

\section{Corresponding Author:}

Bharat Sanga ${ }^{1}$,

Department of Mechanical Engineering,

Guru Nanak Dev Institute of Technology,

Sector-15, Rohini, Delhi-110085, India.

Email: bharatsanga_2k14@dtu.ac.in

\section{Introduction}

Joining and adhesion of parts are essential steps in the assembly of components. Joining of different materials has been a challenging task for engineers for a long time. Many applications in the field of automobiles, aeronautics, electronics, shipbuilding and architecture require joining of dissimilar materials such as metal to non-metal [1]. Miniaturization and weight reduction is a major requirement of today's product development phases. The need is fulfilled by unconventional and newer joining techniques. One such joining technique gaining popularity, particularly in the automotive industry is Ultrasonic Welding (USW) [2].

Introduced in the early 1950s, industrial use of USW has started in the year 1963. It was initially used for wire bonding and tube sealing, but the technique has gained popularity due to its unique advantages such as joining between dissimilar materials, power saving, extremely low welding time and capability to join very thin sheets using lighter and more versatile equipment to produce a stronger, smaller and precise weld $[3,4]$.

In this process, the material to be joined is held together under moderate pressure and a high-frequency ultrasonic vibration is applied locally on the joint. Due to the combined effect of the pressure and ultrasonic vibrations, the surface asperities, contaminants and oxides between the overlapping surfaces get removed and 
the pure metallic surfaces come into contact with each other, resulting in a sound metallurgical bond. The USW is used both for joining of plastic parts as well as metal sheets, popularly known as Ultrasonic Metal Welding (USMW) [5].

Researchers have been investigating different characteristics of USW, but the activities occurring at the joint interface have not been fully explored yet. In this paper, a comprehensive literature review of the joining mechanism taking place in case of USMW has been presented. The selection of study has been focused only on ultrasonic spot or seam welded joints of similar or dissimilar combinations of thin metal sheets. Ultrasonic consolidation or ultrasonic additive manufacturing, ultrasonic wire bonding, ultrasonic plastic welding and ultrasonic hybrid joints (metal to non-metal combinations) are not included in this study.

\section{Theoretical Background}

USW equipment has four main parts (Fig. 1): A Power Supply converts low-frequency electricity (50-60 Hz) to high-frequency electricity $(20-40 \mathrm{kHz})$. The transducer or Signal Converter changes the high-frequency electricity into high-frequency ultrasound waves. A Booster increases the amplitude of the vibrations. Finally, a Horn or Sonotrode focuses the ultrasonic vibrations and delivers them to the materials to be welded. The horn is tuned to operate in the longitudinal mode and its precise design and characterization are required to ensure the required dynamic characteristics of the device. Besides these parts, there is an anvil upon which the materials to be welded are placed and held together during welding with the help of air pressure supplied by a pneumatic system.

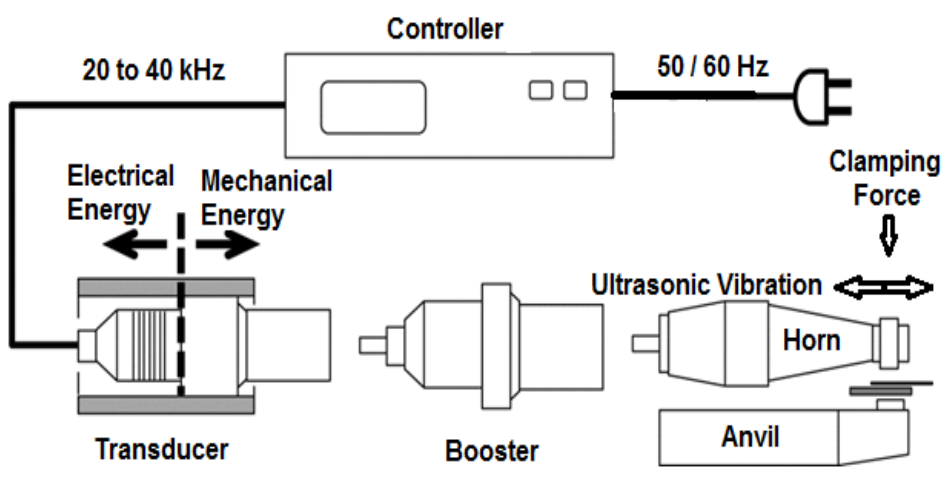

Figure 1: Ultrasonic Metal Welding Set-up

A number of parameters can affect the welding process, such as ultrasonic frequency, vibration amplitude, clamping force, power, energy, welding time, materials, part geometry, and tooling [1,4]. Most USMW systems operate at 20 to $40 \mathrm{kHz}$, with $20 \mathrm{kHz}$ being the most common frequency since, at this frequency, a very high strain rate is achieved in a fraction of a second and the micro-sized interfacial surface asperities are removed instantaneously [5].

\section{Microstructural Analysis}

Microstructural analysis has been the area of interest for the scientists right from the early days of the invention in the field of USW. The works performed by Okada et al. [6], Daniels [7] and Hazlett et al. [8] included fundamental studies on joining of similar and dissimilar combinations of pure metals such as $\mathrm{Al}, \mathrm{Cu}$, $\mathrm{Zn}, \mathrm{Ti}, \mathrm{Be}, \mathrm{Ag}$ and $\mathrm{Ni}$ and alloys like Brass and SS. The sheet thickness had been in the range of 0.06-0.5 $\mathrm{mm}$.

A common observation made by all the above scientists was that the temperature of the interface has reached above the recrystallization temperature and a recrystallization texture was observed but no Inter-Metallic Compound (IMC) or other phases were found to be present at the interface (Fig. 2). However, no common observation was found in regard of inter-atomic diffusion. Inter-atomic diffusion was observed between $\mathrm{Cu}$ and Ti by Okada [6], but the technique used was X-ray micro-analysis. Later, Daniels [7] confirmed that no 
melting or diffusion was observed in $\mathrm{Cu}$ to Ni welding. Hazlett's [8] observations based on Scanning Electron Microscope (SEM) images supported the observations of Daniels [7] to some extent. He concluded that "diffusion" supposed to be the main joining mechanism at the interface was due to grain boundary rather than bulk diffusion. Mechanical mixing at the interface and the accompanying metal bonding at the nascent interface were found to be the main causes of joint formation.

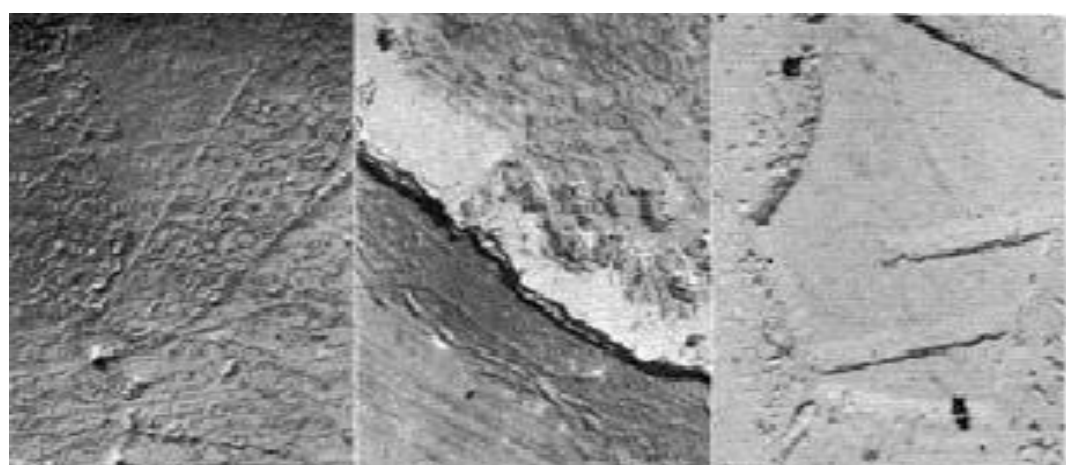

Copper Boundary Titanium

Figure 2: Microstructure of ultrasonically welded $0.5 \mathrm{~mm} \mathrm{Cu}$ and $0.5 \mathrm{~mm}$ Ti showing no IMC or other phases [6]

The findings of $\mathrm{H}$. Kreye [9] were different from that of above researchers. He investigated the joining phenomenon of $\mathrm{Cu}$ and $\mathrm{Al}$ alloy sheets joined by different solid state welding techniques viz. Ultrasonic (sheet thickness: $0.4 \mathrm{~mm}$ ), explosion and friction welding. He found that microstructural changes have occurred during welding, resulting in the formation of new grains along the interface as shown in Figure 3.

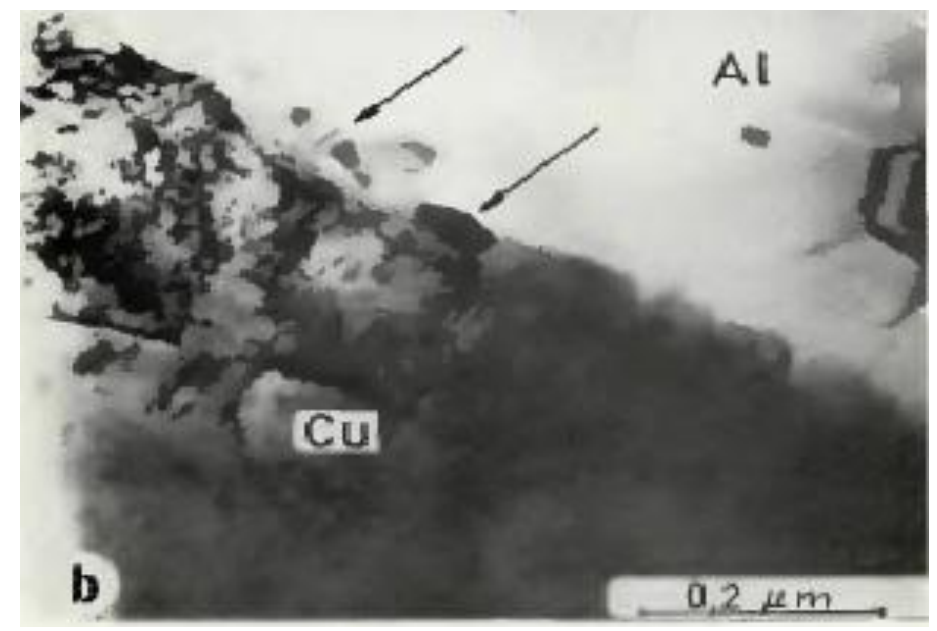

Figure 3: TEM micrograph of US welded $\mathrm{Cu} / \mathrm{Al}$ interface. Arrows show formation of new grains [9]

It was observed during ultrasonic welding that bonding occurred predominantly by melting of a very thin and narrow surface layer (thickness $<1 \mu \mathrm{m}$ ) for a very short time. The small grain size of the particles and Co particles taking more time in dissolution supported this theory. Co particles take more time in dissolution when the temperature of Co reaches above its melting temperature. No IMC was observed due to rapid heat transfer from the bonding area to the surrounding atmosphere. The melting phenomenon was also observed by Y. C. Chen et al. [12] and Bakavos and Pragnell [13].

However, H. Kreye's observation contradicts the joining mechanism explained by many other researchers. Al-Sarraf Z. et al. [10] performed USW with different combinations of $0.1 \mathrm{~mm}$ and $0.5 \mathrm{~mm}$ sheets of $\mathrm{Al}$ and $\mathrm{Cu}$ and found that there was diffusion of $\mathrm{Al}$ on $\mathrm{Cu}$ side. SEM images revealed that more $\mathrm{Al}$ deposited on the $\mathrm{Cu}$ side as compared to less deposition of $\mathrm{Cu}$ on $\mathrm{Al}$ side due to $\mathrm{Cu}$ being a softer metal of the two. But 
definitely, there was an interaction at the atomic level between the atoms of interacting surfaces during ultrasonic welding. This fact was proved by Watanabe T. et al [11]. He used Auger Electron Spectroscopy (AES) to analyze the interface of ultrasonically joined $0.5 \mathrm{~mm}$ thick $\mathrm{Al}$ sheet with Alumina $\left(\mathrm{Al}_{2} \mathrm{O}_{3}\right)$ and observed the formation of a chemical bond between the atoms of $\mathrm{Al}$ and $\mathrm{Oxygen}$ of $\mathrm{Al}_{2} \mathrm{O}_{3}$.

Y. C. Chen et al. [12] and Bakavos and Pragnell [13] studied the interfacial microstructural development in ultrasonic spot welding of $0.93 \mathrm{~mm}$ thick AA6111-T4 automotive sheet and contradicted the general concept that no Heat Affected Zone (HAZ) is present in the USW owing to low-energy input. They have described the term 'Thermo-mechanically Affected Zone' (TMAZ) for the area covered between the sonotrode tip and anvil and 'HAZ' for the area outside the anvil. The same concept was also given by M. Shakil et al. [14]. TMAZ is shown in Figure 4.

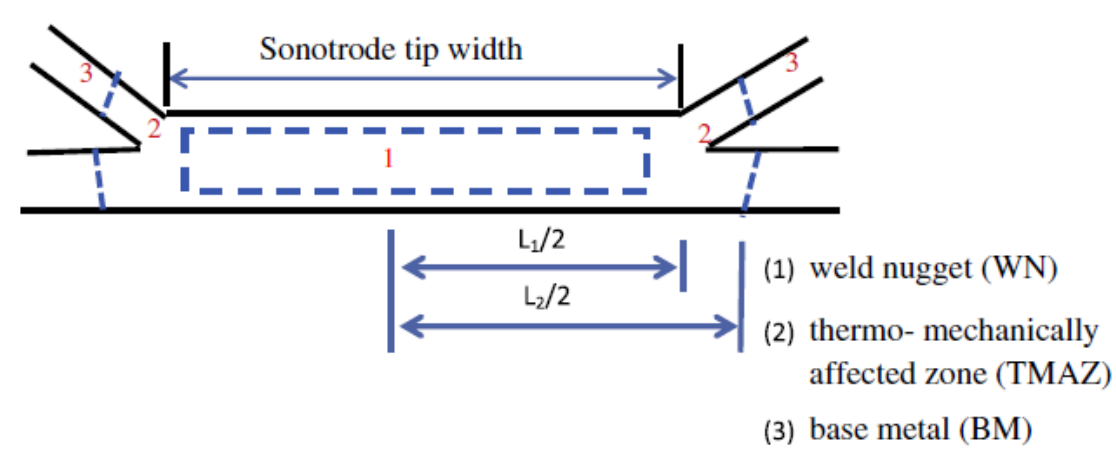

Figure 4: TMAZ was shown [14]

The hardness was low in the centre of the weld area and increased as moved away from the centre. The hardness of the samples was recovered to their normal T4 level after 2 weeks of natural aging. A fine grain boundary precipitation was found when the maximum rise in the temperature was in the range of $250-400$ ${ }^{\circ} \mathrm{C}$. But at a higher temperature level, such as above $500{ }^{\circ} \mathrm{C}$, there was no grain boundary precipitation due to melting and mixing of the parent materials as shown in Figure 5.
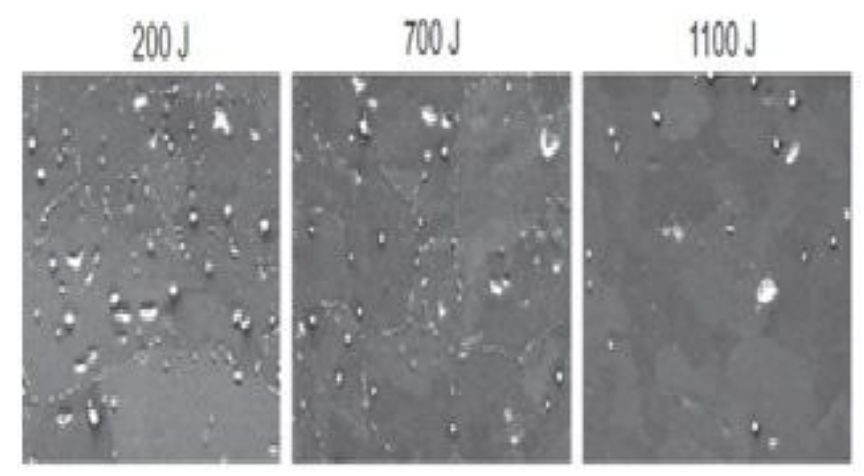

Figure 5: SEM images of grain boundary precipitation in welds produced with increasing energy showing fine grain boundary precipitation [13]

Another aspect observed during this research was that natural aging in AA6111 alloy remained continued even after USW as it would be in normal circumstances for conventional solution treated sheets. This phenomenon was termed as "Accelerated Natural Aging". This concept is also supported by Haddadi [23].

The initiation of the bonding started with the formation of micro-bonds at the points where the oxide was broken or the galling of the asperities occurred. The micro-bond density increases with more energy input and they coalesce to form more bonds. During this initial phase, the bonds break and reform again and the flakes of oxides were also included at the interface. At higher energy level, the swirl-like interface surface gets folded due to the wavelike displacement of intercalated materials (Fig. 6). 


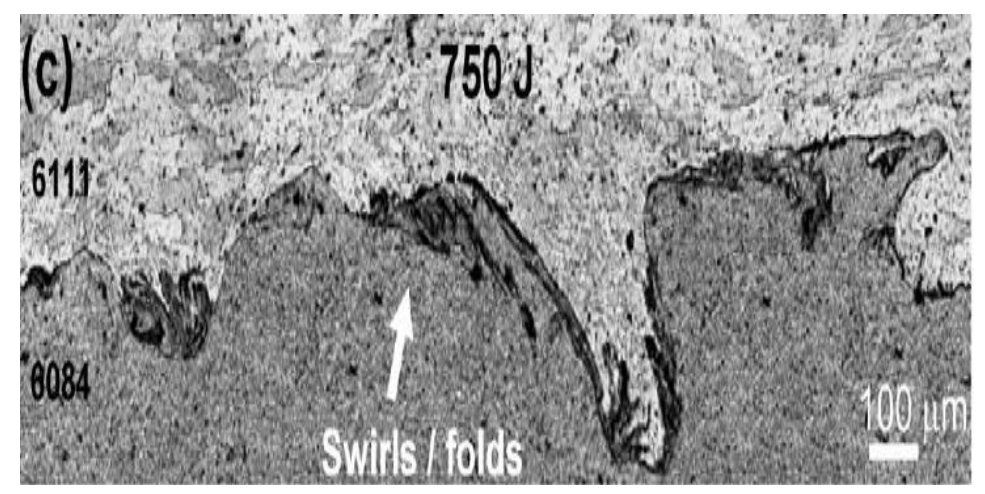

Figure 6: Enlarged region from weld cross section showing interface Swirls/folds [13]

The work of M. Shakil et al. [14] involves USW of $300 \mu \mathrm{m}$ thick sheets of AA3003 alloy and $50 \mu \mathrm{m}$ thick foil of $304 \mathrm{SS}$ alloy using $2.4 \mathrm{~kW}$ ultrasonic spot welding machine. The optical micrographs showed convoluted waves like appearance of weld interface and local micro-welds (Fig. 7) similar to the observations made by Y.C.Chen et al. [12] and Bakavos and Pragnell [13].

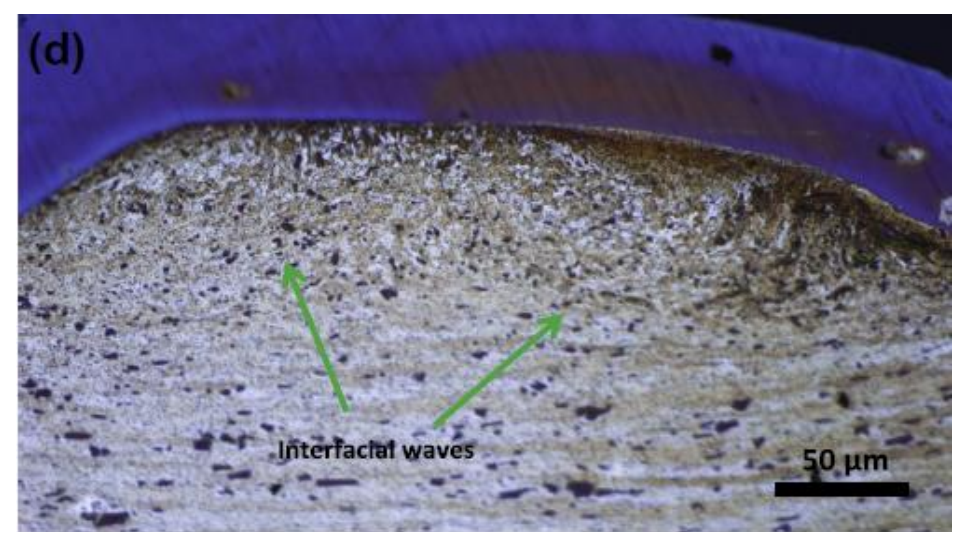

Figure 7: Optical images showing interfacial waves and micro welds [14]

Bonding mechanism was summarized in three steps as (i) the formation and expansion of the bonding line along the weld interface (ii) deformation along the bonding line in TMAZ and (iii) micro-bonding growth between the materials. It was also observed that the elongated grain microstructures disappear, and recrystallization takes place by plastic deformation. Hence, it was concluded that the material at the interface receives more ultrasonic energy and its temperature rises continuously due to which instant work hardening and softening take place simultaneously. Thus, it was compared with the cold work followed by annealing process.

Recovery and recrystallization were also observed by J. Magin et al. [15] during the ultrasonic torsion welding of $0.8 \mathrm{~mm}$ thick pure aluminum sheet AA1199 and commercially pure Titanium grade $1 \mathrm{Ti}$ sheet. It was confirmed that melting did not take place and the joint was formed well below the melting point in solid state without the formation of any IMCs. Similar results were also derived by Zhang C. and Li L. [16] during USW of Al foils. They simulated the coupled thermo-mechanical fields using a 3-D Finite Element Analysis (FEA) model to study the effect of heat generation and plastic deformation at the interface and concluded that it is only the severe, localized plastic deformation which is responsible for the bond formation.

The work of C.Q. Zhang et al. [17,18] explored USW of $0.93 \mathrm{~mm}$ thick Al alloy AA6111-T4 and $1.0 \mathrm{~mm}$ thick Ti alloy $\mathrm{TiAl}_{6} \mathrm{~V}_{4}$ in 2014 and again $1.0 \mathrm{~mm}$ thick $\mathrm{Al}$ alloy AA2139-T8 and $1.0 \mathrm{~mm}$ thick Ti alloy $\mathrm{TiAl}_{6} \mathrm{~V}_{4}$ in 2016. Almost similar results were obtained. No visible IMC layer was detected. It was observed that $\mathrm{Al}$ grains near the weld interface have been distinctly refined by the ultrasonic spot welding process, but 
there was no difference in the grains of $\mathrm{TiAl}_{6} \mathrm{~V}_{4}$. Grain refinement was also observed by Prangnell et al. [19] during USW of $1.0 \mathrm{~mm}$ thick Al 6111 sheet with automotive DC04 steel sheet. However, Zhang suggested that little deformation occurred on the Ti side due to its high strength at peak temperature. The absence of IMC in Al-Ti combination was attributed to three factors: (i) very less solid solubility (ii) relatively high activation energy and (iii) the higher energy barrier to nucleation of the IMC phase. In a similar work done by Zhu Z. et al. [20] on AA6061 and $\mathrm{TiAl}_{6} \mathrm{~V}_{4}$, it was observed that diffusion across the interface took place and thickness of diffusion layer increased with increasing welding time. No description of IMCs formed during the process was given. Frank Balle et al. [21] also ultrasonically welded $1.0 \mathrm{~mm}$ thick Al alloy AA7075 and $\operatorname{TiAl}_{6} \mathrm{~V}_{4}$ and observed formation of micro-welds which spread along the joint interface leading to the solid state joint formation. However, they did not investigate any IMC or reaction layer in their work.

The findings of S.Q. Wang et al. [22] were contradictory to that of C.Q. Zhang et al. [17,18]. The ultrasonic joining of $1.5 \mathrm{~mm}$ thick AA 5754 alloy and $1.0 \mathrm{~mm}$ thick $\mathrm{TiAl}_{6} \mathrm{~V}_{4}$ alloy with an interlayer of $75 \mu \mathrm{m}$ thick $\mathrm{Al}$ was performed. SEM and X-ray Diffraction (XRD) analysis of the microstructure revealed that IMC was formed, but out of many possible combinations, only $\mathrm{TiAl}_{3} \mathrm{IMC}$ phase was present due to its ease of formation at a comparatively low temperature as shown in Figure 8. The joint mechanism was attributed to the melting of the $\mathrm{Al}$ interlayer and $\mathrm{Al}$ alloy. However, Ti alloy, being harder than $\mathrm{Al}$, was not found in the molten form, but got dissolved in the liquefied $\mathrm{Al}$ at that temperature.

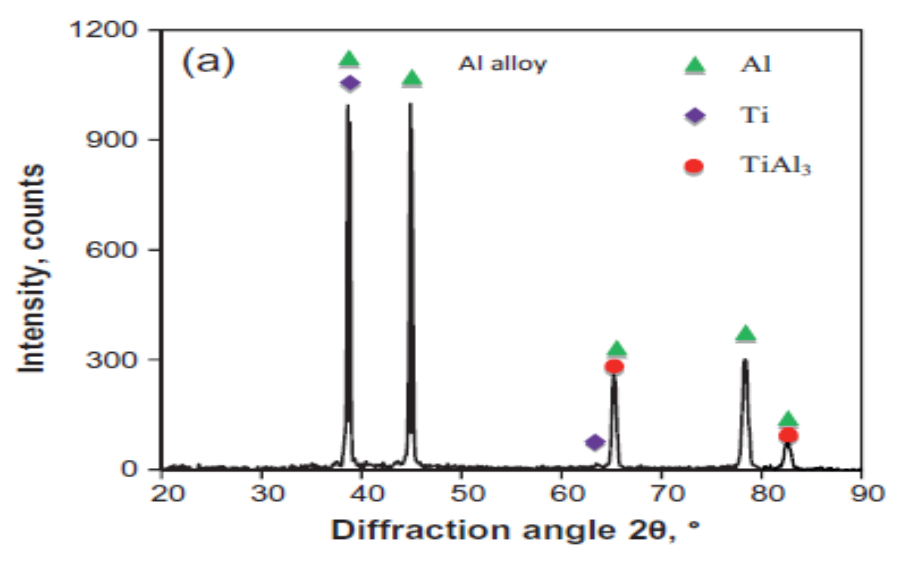

Figure 8: XRD pattern of ultrasonic welded $\mathrm{Al} / \mathrm{Ti}$ alloy joint with $\mathrm{Al}$ interlayer [22]

Ultrasonic weldability of $\mathrm{Al}$ alloy AA6111-T4 with bare and zinc coated Steel of approximately $1 \mathrm{~mm}$ thickness was investigated by Haddadi and Abu-Farha [23]. Their investigation in reference of IMCs, also supported the findings of S.Q. Wang et al. [22]. The growth of Al-Fe intermetallic layer was seen spreading discontinuously along the interface. The presence of IMC was verified by the Energy Dispersive Spectroscopy (EDS) analysis. Several Al-Fe IMCs such as $\mathrm{FeAl}_{3}, \mathrm{Fe}_{2} \mathrm{Al}_{5}$ and $\mathrm{FeAl}$ were observed, $\mathrm{Fe}_{2} \mathrm{Al}_{5}$ having the largest proportion. The formation of the IMCs was co-related to the fracture of the joint in lapshear test. At sufficiently high weld time, the failure occurred by cracking through the interface of the reaction layer and the steel sheet where brittle FeAl phase was formed. A significant HAZ/TMAZ was also observed like Y.C. Chen [12], D. Bakavos and P.B. Pregnell [13] and M. Shakil [14].

Shin-ichi Matsuoka et al. [24] joined same and different combinations of Al alloys (AA1050H-24, AA1050-O and $\mathrm{AA} 3003-\mathrm{O})$ and $\mathrm{Cu}$ alloy (C1020) of thickness ranging from $0.3 \mathrm{~mm}$ to $1.5 \mathrm{~mm}$. The SEM observation of weld between AH/A1-O showed that the welding interface had no defects such as cracks or exfoliation. The presence of oxides or organic films was observed in incomplete welding regions, but the interface of good weld was free from such defects. The surface in the vicinity of the joint appeared as pleat-like traces due to pressure and frictional heat of the horn. Energy Dispersive X-ray (EDX-ray) analysis observed the presence of a transit layer of approximately $2 \mu \mathrm{m}$ thickness on both sides of the interface which indicates the possibility of formation of some reaction or diffusion layer (Fig.9). Formation of IMCs or other welding attributes such as HAZ/TMAZ were not explored. 


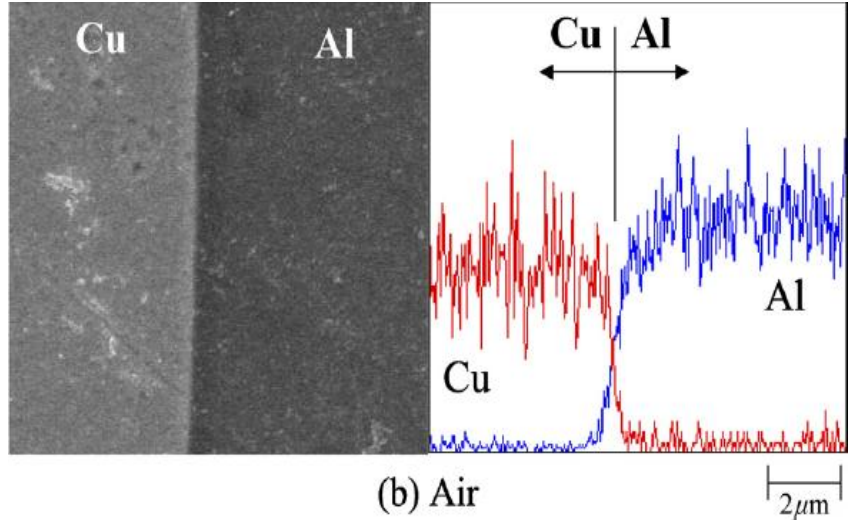

Figure 9: SEM image showing formation of $2 \mu$ thick transit layer of both alloys ( $\mathrm{Al} / \mathrm{Cu}$ ) [24]

Fujii [25] ultrasonically joined $1.0 \mathrm{~mm}$ thick sheets of AA1050 Al alloy and $\mathrm{Cu}$. He strongly advocated the recrystallization of grains at the interface. Recrystallization was attributed to the creation of large dislocation density due to deformation of the grains. The thickness of the reaction layer of $\mathrm{Al}_{2} \mathrm{Cu}$ IMC phase was found to be in the range of 40-100 $\mathrm{nm}$ and it helped in increasing the joint strength, unlike normal IMC, due to its very less thickness $(<1 \mu \mathrm{m})$. The same observations were made by the same author [26] during the USW of 1.0 $\mathrm{mm}$ thick AA6061 Al alloy and $0.5 \mathrm{~mm}$ thick $304 \mathrm{SS}$ sheets where a number of nanometer-size Fe-Al IMC formed discontinuously around the interface and contributed to the weld strength. The formation of $\mathrm{Fe}-\mathrm{Al}$ IMC was attributed to pipe diffusion of $\mathrm{Fe}$ in $\mathrm{Al}$ around the interface due to excessive dislocation density at the interface owing to severe shear deformation during USW (Fig. 10). The effects of excessive dislocation density were explained in detail by Gunduz et al. [38].

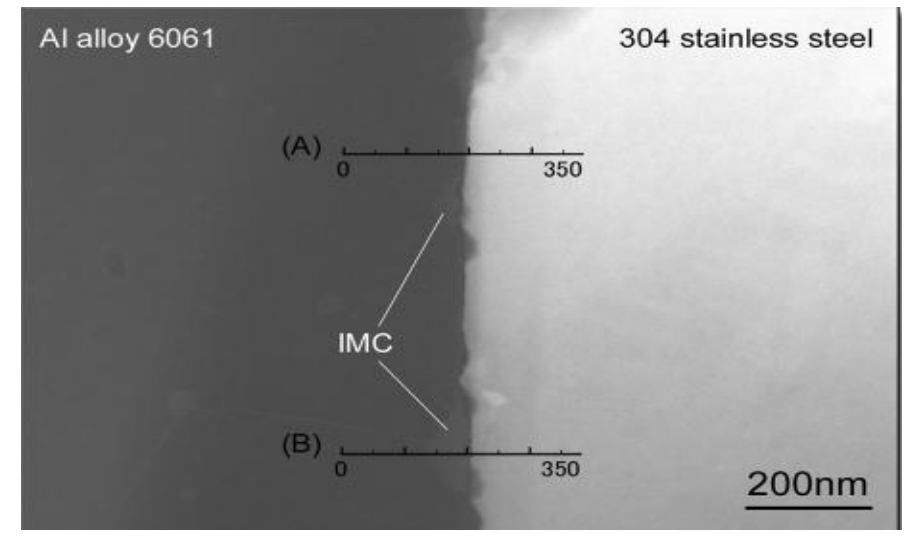

Figure 10: TEM image around the weld interface showing a thin layer of IMC [26]

During the similar experiment done by Y. Y. Zhao et al. [27] the ultrasonic joint was made between $1.0 \mathrm{~mm}$ thick sheet of AA 6061 and pure $\mathrm{Cu}$. The joint formation was attributed to micro-welds at low energy input, but at higher energy input, deformation along with mechanical interlocking due to formation of swirl like pattern along the interface was found to be the main cause of joint formation. The joint strength increased with increasing welding energy but decreased at very high levels of welding energy. Similarly, no IMCs were observed at lower values of welding energy, but a very thin dark layer of $\mathrm{Al}_{4} \mathrm{Cu}_{9} \mathrm{IMC}$ was found at very high energy level.

C.Y. Zhang et al. [28] and Xin Wu et al. [29] observed similar characteristics of interface during USW. C.Y. Zhang et al. [28] while doing the ultrasonic spot welding on a 2-mm thick wrought AA5754-O Al alloy sheet revealed through SEM images that as the energy input was increased; the waviness, branching, bifurcation and pores at the interface decreased and the strength of the joints increased. Xin Wu et al. [29] also observed the similar results during the USW of battery tabs made of $\mathrm{Al}$ and $\mathrm{Cu}$. Highly wavy, curly and intermixed layers of Al were observed. However, the observations of R. Jahn [30] contrasted with the above and showed 
that waviness, branching and bifurcation at the interface increased with higher energy during the USW of 0.9 mm thick Al alloy AA6111-T4.

R. Balasundaram et al. [31] conducted experiments on $\mathrm{Al}$ alloy and $\mathrm{Cu}$ alloy, with and without $\mathrm{Zn}$ inter-layer. $1.5 \mathrm{~mm}$ thick sheet of AA5754-O and $1 \mathrm{~mm}$ thick sheet of $\mathrm{C} 110 \mathrm{Cu}$ alloy and $50 \mu \mathrm{m}$ thick pure Zn interlayer were used for experimentation. The SEM micrographs revealed swirling interface with the void when sheets were joined without interlayer, however, a flat and tight interface was obtained with $\mathrm{Zn}$ inter-layer. Secondly, no IMCs were produced without inserting $\mathrm{Zn}$ inter-layer, but a discontinuous IMC layer of $\mathrm{Al}_{2} \mathrm{Cu}$ was observed mostly at $\mathrm{Cu}$ side due to higher solubility of $\mathrm{Al}$ in $\mathrm{Cu}$ when welded with $\mathrm{Zn}$ inter-layer (Fig. 11). Another aspect observed was the possibility of Liquid Metal Embrittlement (LME) where liquid Zn could embrittle $\mathrm{Cu}$ and a crack could be induced.
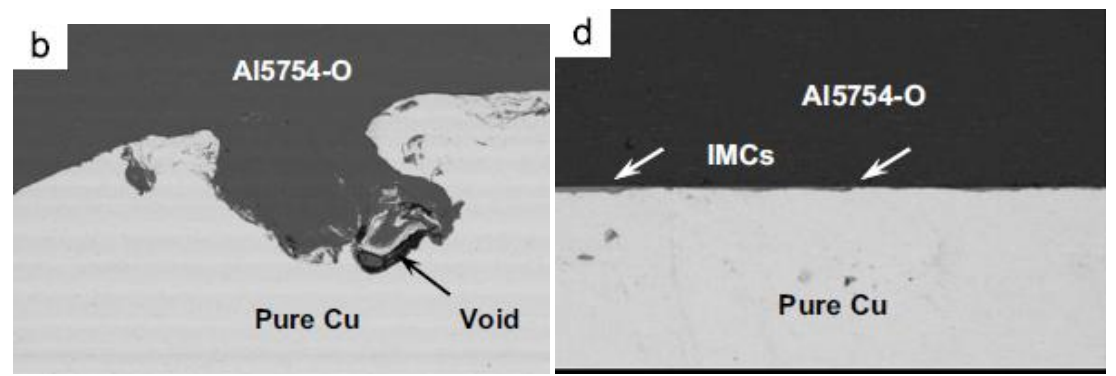

Figure 11: Micrographs showing Swirling interface in (b) and flat interface in (d). IMCs in $\mathrm{Al}$ alloy/Cu joints with Zn inter-layer shown in (d) [31]

The interface characteristics were also explored during the USW performed between different metals combined with $\mathrm{Mg}$ alloys. Formation of brittle IMCs was explored by A. Panteli et al [32] during the ultrasonic joining of $1.0 \mathrm{~mm}$ thick sheets of Al alloy AA6111 and Mg alloy AZ31-H24. He clearly observed thick layers of IMCs $\mathrm{Al}_{3} \mathrm{Mg}_{2}$ and $\mathrm{Al}_{12} \mathrm{Mg}_{17}$. The thickness of the IMCs increased with increasing welding energy. The rapid growth rate of IMC layers was attributed to the enhanced diffusion due to micro-cracking in the brittle reaction layer. They also observed the melting at the interface between the IMC phase and the $\mathrm{Mg}$ alloy base at higher energy levels and at decreased melting temperature.

V. K. Patel et al. [32,33,34] conducted many experimentations to study the weldability aspect of ultrasonically welded $\mathrm{Mg}$ alloy AZ31-H24 in similar and dissimilar combinations with other metals and with or without using interlayer. During the USW of $2 \mathrm{~mm}$ thick sheet of $\mathrm{Mg}$ alloy AZ31-H24 at different energy levels, he observed the complete recrystallization of microstructure and the grain size increased with respect to the increase in energy level (Fig. 12).
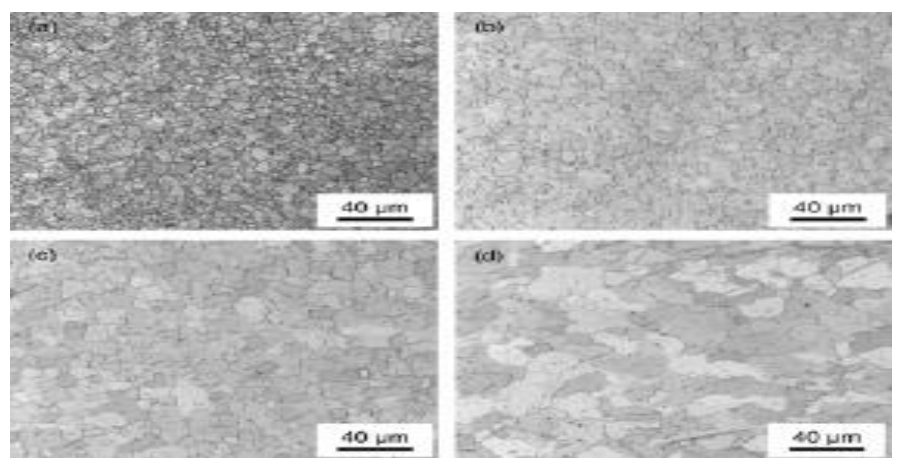

Figure 12: Microstructure of AZ31 at different energy levels compared to the base metal [32]

In another study [33] on the USW of $2 \mathrm{~mm}$ thick sheet of AZ31B-H24 Mg alloy and $0.8 \mathrm{~mm}$ thick sheet of High Strength Low Alloy (HSLA) with the $70 \mu \mathrm{m}$ thick pure zinc sheet placed in-between as an interlayer, he observed very thin IMCs such as $\mathrm{Mg}_{2} \mathrm{Zn}_{11}, \mathrm{Mg}_{7} \mathrm{Zn}_{3}, \mathrm{MgZn}$ and $\mathrm{MgZn}_{2}$ between $\mathrm{Mg}$ and $\mathrm{Zn}$ substrates but no IMCs were observed between $\mathrm{Zn}$ and Fe. Also, no oxide was found at the $\mathrm{Mg}$ / steel interface (Fig. 13). 


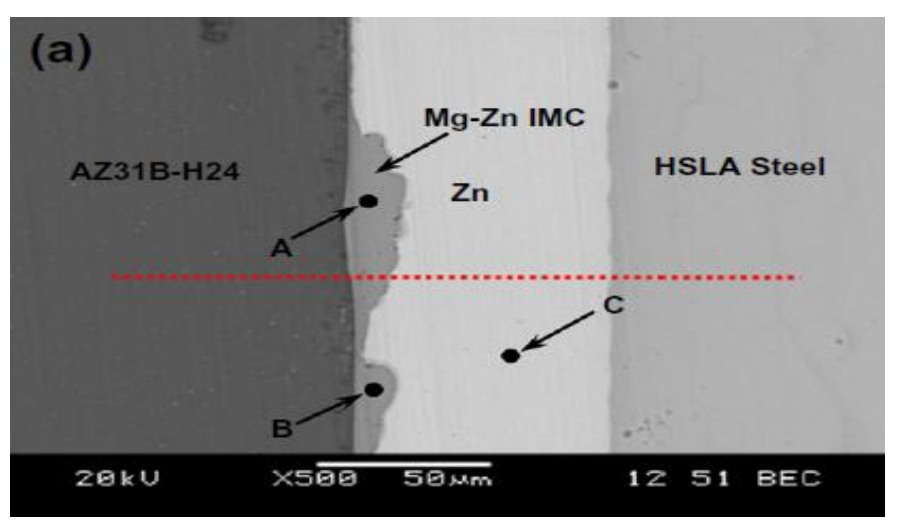

Figure 13: Microstructure of ultrasonic welded Mg/HSLA with $\mathrm{Zn}$ inter-layer showing IMCs between $\mathrm{Zn}$ and $\mathrm{Mg}$ alloy, but no IMCs on HSLA side [33]

So it was suggested that the joint at the steel side was formed by solid solution of $\mathrm{Zn}$ and Fe. However, during the similar studies conducted by the same researcher earlier (2012) with $2 \mathrm{~mm}$ thick AZ31B-H24, $1.5 \mathrm{~mm}$ thick AA5754-O and $50 \mu \mathrm{m}$ thick pure Sn interlayer [34], it was observed that IMCs form at interface without using the interlayer but no brittle IMCs formed when Sn interlayer was placed in between. This improvement was attributed to the formation of solid solutions of $\mathrm{Sn}$ with $\mathrm{Mg}$ and $\mathrm{Al}$ and due to formation of eutectic structure such as $\mathrm{Mg}_{2} \mathrm{Sn}$ in the interlayer (Fig. 14). The joint strength was improved as observed by Fujii [24].

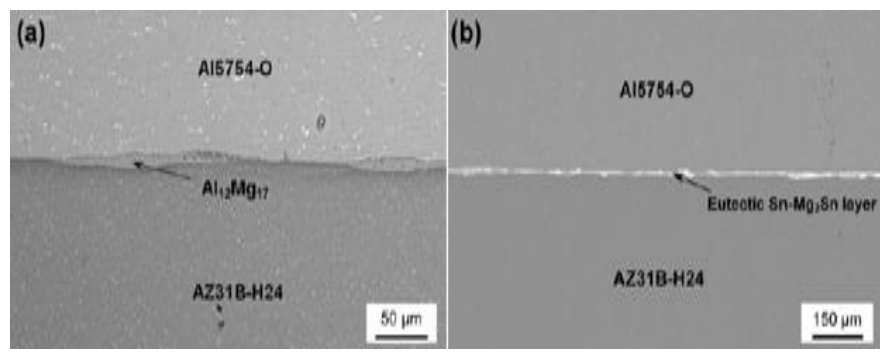

Figure 14:(a) Micrograph showing interface with IMCs without using interlayer (b) formation of solid solution of $\mathrm{Sn}$ with $\mathrm{Mg}$ and $\mathrm{Al}$ at the interface [34]

Similar observations were made by Watanabe et al. [35] while making USW joints with $0.8 \mathrm{~mm}$ thick SS400 mild steel sheet and $1.2 \mathrm{~mm}$ thick AA5052-H24 Al alloy sheet containing Mg with and without using commercially pure AA1050 alloy having $1.2 \mathrm{~mm}$ thickness as an insert material. It was observed that the strength decreased due to the formation of IMC $\mathrm{Fe}_{2} \mathrm{Al}_{5}$ at the interface when welded at high welding time without using insert material. Use of insert material improved the joint strength significantly since no IMCs were formed even at a higher welding time between the interfaces of SS400/AA1050 and AA1050/AA5052 (Fig. 15).

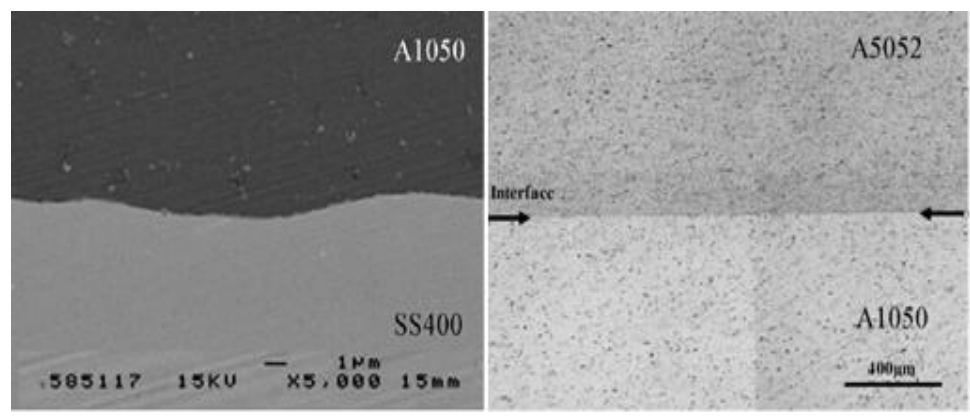

Figure 15: SEM image showing no IMCs produced at the interfaces with insert material [35] 
Similar investigations were made on interface microstructure of $\mathrm{Mg}$ alloy/Cu combination by Macwan and Chen [36]. Dissimilar pairs of $2 \mathrm{~mm}$ thick AZ31B-H24 and $1 \mathrm{~mm}$ thick pure $\mathrm{Cu}$ were ultrasonically welded. Continuously increasing diffusion layer of IMCs at the interface was observed on the Mg side, but not on the $\mathrm{Cu}$ side, due to higher melting temperature and thermal conductivity of $\mathrm{Cu}$. Interface thickness increased with increasing temperature (Fig. 16).
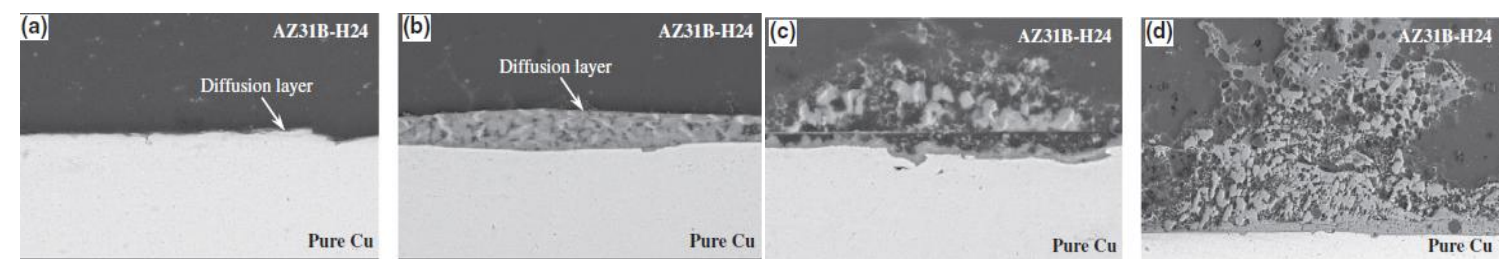

Figure 16: Micrographs showing increasing diffusion thickness at the interface [36]

The interface consisted of eutectic structure of $\mathrm{Mg}$ and $\mathrm{Mg}_{2} \mathrm{Cu}$. The thickness of diffusion layer was observed significantly larger as compared to other instances. This enhanced dynamic diffusion was attributed to the diffusion-induced vacancies, the phenomena, also observed by I. E. Gunduz et al [37] during the US welding of $50 \mu \mathrm{m}$ thick $1100-\mathrm{H} 19 \mathrm{Al}$ foil and $250 \mu \mathrm{m}$ thick $99.8 \%$ pure Zinc sheet. Fujii et al [24] also observed the same phenomenon in their work. A large reduction in the melting point was observed due to strain-induced excess vacancy that resulted in local melting at the interface even at lower temperature and short welding time in USW.

M. P. Satpathy et al. [38] explored the welding interface during the USW of $0.3 \mathrm{~mm}$ thick sheets of Al alloy AA1100 and UNS C27000 Brass and categorized the joint as "under", "good" and "over" on the basis of the condition of the interface. A good weld had high density of micro-bonds and was free from gaps between sheets. Inter-atomic diffusion was observed as the main reason for joint formation.

\section{Observations}

This review paper critically reviews the observations made by researchers regarding the joining mechanism and the characteristics of the joint interface produced by ultrasonic metal welding of similar as well as dissimilar metal combinations. The following observations are made:

1. The bonding mechanism in USW has been the core interest for many researchers, but still, no common consensus on this issue has been made.

2. Following bonding mechanisms were observed- Interatomic diffusion $[5,7,9,19,23,31,32,33,34,36,37,38]$, recrystallization and recovery $[13,14,24,32,33]$, melting at the interface $[8,12,21,22,30,31]$ mechanical mixing/interlocking at interface $[7,26]$, and micro-welding $[11,13,20,26]$.

3. No IMCs were observed in the combinations of pure metal such as $\mathrm{Cu}, \mathrm{Ti}, \mathrm{Ag}, \mathrm{Be}, \mathrm{Al}, \mathrm{Ni}, \mathrm{Zn}[5,6,7,8,9]$.

4. IMCs were observed in the combinations of AA6111 and $\mathrm{Zn}$ coated Steel [22], AA5754 and $\mathrm{TiAl}_{6} \mathrm{~V}_{4}$ [21], AZ31B and HSLA [33] and AA5052 and SS400 [35], AA6061 and SS304 [25], AA6061 and Pure Cu [26], $\mathrm{Al}$ alloy and $\mathrm{Cu}$ alloy with $\mathrm{Zn}$ as inter-layer [30], Al alloy AA6111 and $\mathrm{Mg}$ alloy AZ31-H24 [31].

5. Formation of thick layers of brittle IMCs can be avoided by using some suitable interlayer [34]. Nevertheless, thin layer of IMCs contributed to the strength of the joint [24, 25].

6. Few researchers observed $\operatorname{HAZ}$ and $\operatorname{TMAZ}[11,13,22]$ contradicting the conventional concept of the absence of HAZ / TMAZ in solid state welding.

7. Joint failures were attributed to the presence of IMCs [21, 22, 25]. 
8. Enhanced diffusion was observed due to diffusion induced vacancies [24, 25, 31, 37].

9. Characterization of the interface as described by many researchers is - convoluted wavelike or swirling, branched, bifurcated and free from any cracks, exfoliation or oxides [13, 23, 27, 28, 29, 30].

\section{Conclusions}

All the studies have shown that there are many mechanisms working behind the formation of the ultrasonically welded joint. In some combinations, there are more than one joining mechanisms taking place, whereas in other cases, there is only one. Secondly, different metal combinations show the different possibilities of joining mechanisms. Still, there is ample scope for finding some uniform theory which can predict the joint mechanism.

It can be concluded that IMCs are formed in the dissimilar combinations of metals or alloys which reduce the joint strength in most of the cases but a suitably chosen inter-layer may improve the joint strength in some of the metal combinations by making a very thin layer of IMCs of the parent metals.

A unique concept of enhanced dynamic diffusion due to accelerated dislocation assimilation has been found to be the main cause of severe deformation taking place during ultrasonic welding. This phenomenon reduces the melting point of the parent metals and promotes the 'welding due to melting' concept contradicting the 'no melting in cold welding'. Similarly, the presence of HAZ and TMAZ indicates that ultrasonic metal welding may be assumed to be an extension of fusion welding and opens the need for further exploration.

\section{References:}

[1] Elma Kicukov and Ali Gursel, "Ultrasonic welding of dissimilar materials: A review," Periodicals of Engineering and Natural Sciences, Vol. 3, No. 1, pp. 28-36, 2015.

[2] K. Graff, Ultrasonic Metal Welding, New Developments in Advanced Welding, Cambridge, pp. 241-269, 1997.

[3] American Welding Society Handbook, Vol. 2, $8^{\text {th }}$ ed., 1997.

[4] C. F. Brockelsby, “Some Applications of Ultrasonics,” J. Sci. Instrum., 40, pp. 153-157, 1963.

[5] E. De Vries, Mechanics and Mechanisms of Ultrasonic Metal Welding, Ph.D. Thesis, Ohio State University, 2004.

[6] Minor Okada, S. Shin, M. Miyagi and H. Matsuda, "Joint mechanism of ultrasonic welding," Journal of Japan Institute of Metals, 4(26), pp. 250-256, 1962.

[7] H. P. C. Daniels, “Ultrasonic Welding,” Ultrasonics, pp. 190-196, 1965.

[8] T. H. Hazlett and S. M. Ambekar, "Additional Studies on Interface Temperatures and Bonding Mechanisms of Ultrasonic Welds,” Welding Research Supplement, AWS, pp. 196s-200s, 1970.

[9] H. Kreye, "Melting Phenomena in Solid State Welding Processes," Welding Research Supplement, AWS, pp. 154-s to 158 -s, 1977.

[10] Z. Al-Sarraf and M. Lucas, "A study of weld quality in ultrasonic spot welding of similar and dissimilar metals," Modern Practice in Stress and Vibration Analysis, Journal of Physics: Conference Series, 382, pp. 1-6, 2012. 
[11] T. Watanabe, A. Yanagisawa and S. Sunaga, "Auger Electron Spectroscopy Analysis at the Ultrasonically Welded Interface between Alumina and Aluminum," Metallurgical and Materials Transactions A, 34(A), pp. 1107-1111, 2003.

[12] Y. C. Chen, D. Bakavos, A. Gholinia and P. B. Pragnell, "HAZ development and accelerated post-weld natural ageing in ultrasonic welding aluminium 6111-T4 automotive sheet," ActaMaterialia, 60, pp. 2816-2828, 2012.

[13] D. Bakavos and P. B. Pragnell, "Mechanism of joint and microstructure formation in high power ultrasonic spot welding 6111 aluminium automotive sheet," Material Science and Engineering A, 527, pp. 6320-6334, 2010.

[14] M. Shakil, N. H. Tariq, M. Ahmed, M. A. Choudhary, J. I. Akhter and S. S. Babu, "Effect of ultrasonic welding parameters on microstructure and mechanical properties of dissimilar joints," Materials and Design, 55, pp. 263-273, 2014.

[15] J. Magin and F. Balle, "Solid state joining of aluminum, titanium and their hybrids by ultrasonic torsion welding," Mat.-wiss.u.Workstofftech, 45(12), pp. 1072-1083, 2014.

[16] C. Jhang and L. Li, "A Coupled Thermal-Mechanical Analysis of Ultrasonic Bonding Mechanism," Metallurgical and Materials Transactions B, 40(B), pp. 196-207, 2009.

[17] C. Q. Zhang, J. D. Robson, O. Ciuca and P. B. Pregnell, "Microstructural characterization and mechanical properties of high power ultrasonic spot welded aluminum alloy AA6111-TiAl6V4 dissimilar joints," Materials Characterization, 97, pp. 83-91, 2014.

[18] C. Q. Zhang C. Q., J. D. Robson and P. B. Pregnell, "Dissimilar ultrasonic spot welding of aerospace aluminum alloy AA2139 to titanium alloy TiA16V4," Journal of Materials Processing Technology, 231, pp. 382-388, 2016.

[19] P. Pragnell, F. Haddadi and Y. C. Chen, "Ultrasonic spot welding of aluminum to steel for automotive applications-microstructure and optimization," Materials Science and Technology, 27(3), pp. 617-624, 2011.

[20] Zhu, K. Y. Lee and X. Wang, "Ultrasonic welding of dissimilar metals, AA6061 and Ti6A14V," Int J Adv Manuf Technol, 59, pp. 569-574, 2012.

[21] F. Balle and J. Magin, "Ultrasonic spot and torsion welding of aluminium to titanium alloy: Process, properties and interfacial microstructure," Physics Procedia, 70, pp. 846-849, 2015.

[22] S. Q. Wang, V. K. Patel, S. D. Bhole, G. D. Wen and D. L. Chen, "Microstructure and mechanical properties of ultrasonic spot welded Al/Ti alloy joints," Materials and Design, 78, pp. 33-41, 2015.

[23] F. Haddadi and F. Abu-Farha, "Microstructural and mechanical performance of aluminum to steel high power ultrasound spot welding," Journal of Materials Processing Technology, 225, pp. 262-274, 2015.

[24] Shin-ichi Matsuoka and H. Imai, "Direct welding of different metals used ultrasonic vibration," Journal of Material Processing Technology, 209, pp. 954-960, 2009.

[25] Hiromichi T. Fujii, Y. Goto, Y. S. Sato and H. Kokawa, "Microstructural evolution in dissimilar joint of $\mathrm{Al}$ alloy and Cu during ultrasonic welding," Materials Science Forum, 783, pp. 2747-2752, 2014. 
[26] Hiromichi T. Fujii, Y. Goto, Y. S. Sato and H. Kokawa, "Microstructure and lap shear strength of the weld interface in ultrasonic welding of Al alloy to stainless steel," Scripta Materialia, 116, pp. 135-138, 2016.

[27] Y. Y. Zhao, D. Li, and Y. S. Zhang, "Effect of welding energy at interface zone of Al-Cu ultrasonic welded joint," Science and Technology of Welding and Joining, 18 (4), pp. 354-360, 2013.

[28] C. Y. Zhang, D. L. Chen and A. A. Luo, "Joining 5754 Automotive Aluminum Alloy 2-mm Thick Sheets Using Ultrasonic Spot Welding,” Welding Journal, 93, pp. 131s-138s, 2014.

[29] Xin Wu, Tang Liu and Wayne Cai, "Microstructure, welding mechanism and failure of Al/Cu ultrasonic welds," Journal of Manufacturing Processes, Vol. 20, pp. 321-331, 2015.

[30] R. Jahn, R. Cooper and D. Wilkosz, "The Effect of Anvil Geometry and Welding Energy on Microstructures in Ultrasonic Spot Welds of AA6111-T4," Metallurgical and Materials Transactions A., 38(A), pp. 570-583, 2007.

[31] R. Balasundaram, V. K. Patel, S. D. Bhole and D. L. Chen, "Effect of Zinc interlayer on ultrasonic spot welded aluminium to copper joints," Material Science and Engineering A, 607, pp. 277-286, 2014.

[32] Panteli, J. D. Robson and P. B. Pragnell, "The effect of high strain rate deformation on intermetallic reaction during ultrasonic welding aluminum and magnesium," Materials Science \& Engineering A, 556, pp. 31-42, 2012.

[33] V. K. Patel, S. D. Bhole and D. L. Chen, "Influence of ultrasonic spot welding on microstructure in a magnesium alloy," Scripta Materialia, 65, pp. 911-914, 2011.

[34] V. K. Patel, S. D. Bhole and D. L. Chen, "Formation of zinc interlayer texture during dissimilar ultrasonic spot welding of magnesium and high strength low alloy steel," Materials and Design, 45, pp. 236-240, 2013.

[35] V. K. Patel, S. D. Bhole and D. L. Chen, "Improving weld strength of Magnesium to Aluminium dissimilar joints via Tin interlayer during ultrasonic spot welding," Science and Technology of Welding and Joining, 17(5), pp. 342-347, 2012.

[36] T. Watababe, H. Sakuyama and A. Yanagisawa, "Ultrasonic welding between mild steel sheet and AlMg alloy sheet," Journal of Materials Processing Technology, 209, pp. 5475-5480, 2009.

[37] A. Macwan and D. L. Chen, "Microstructure and mechanical properties of ultrasonic spot welded copper-to-magnesium alloy joints," Materials and Design, 84, pp. 261-269, 2015.

[38] Ibrahim E. Gunduz, T. Ando, E. Shattuck, P. Y. Wong and C. C. Doumanidis, "Enhanced diffusion and phase phase transformations during ultrasonic welding of zinc and aluminium," Scripta Materialia, 52, pp. 939-943, 2005.

[39] M. P. Sathpathy, B. R. Moharana, S. Dewangan and S. K. Sahu, " Modeling and optimization of ultrasonic metal welding on dissimilar sheets using fuzzy based genetic algorithm approach," Engineering Science and Technology, an International Journal, Vol. 18, pp. 634-647, 2015. 